Toxicology in Vitro Volume 20, Issue 1 , February 2006, Pages 52-62

doi:10.1016/j.tiv.2005.06.002

Copyright (c) 2005 Elsevier Ltd All rights reserved.

\title{
Signal transduction pathways involved in particulate matter induced relaxation in rat aorta-Spontaneous hypertensive versus Wistar Kyoto rats
}

\author{
K. Bagate ${ }^{a}$, J.J. Meiringa ${ }^{a}$ M.E. Gerlofs-Nijland ${ }^{b}$, F.R. Cassee $^{b}$ and P.J.A. \\ Borm $^{\mathbf{a}_{1}}$
}

aparticle Research, Institut fur Umweltmedizinische, Forschung (IUF) at the University of Düsseldorf, NRW, Germany

${ }^{\mathrm{b}}$ Centre of Environmental Health Research, National Institute for Public Health and the Environment (RIVM), Bilthoven, The Netherlands

* Corresponding author. Address: Centre of Expertise in Life Sciences, Zuyd University, 6400 AN, Heerlen, The Netherlands. Tel.: +31 454006800.

\begin{abstract}
Previously we reported that in vivo exposure to ambient particulate matter (PM) induces vasodilatation in rat aorta. The purpose of the current study was to investigate the intracellular messengers involved in PM-elicited vasodilatation in aortas from spontaneous hypertensive (SHR) and normotensive (WKY) rats.
\end{abstract}

\section{Methods}

The contribution of three different intracellular pathways, i.e. (1) the NO-cGMP pathway, (2) prostanoids signaling and (3) endothelial hyperpolarisation factors were evaluated by using specific inhibitors (NS2028, Diclofenac and high Kconcentration/17-ODYA, respectively). Using antagonists of capsaicin- or histamine receptors we tested potential interactions of PM with these receptors. Particle suspensions (EHC-93), particle filtrates (particle-free) and $\mathrm{Cu}^{2+}-$ or $\mathrm{Zn}^{2+}-$ containing solutions were used to obtain cumulative dose-response curves of relaxation in normal and endothelium-denuded rings.

\section{Results}

Our present data confirm that PM and its soluble components elicit an endothelium-independent vasodilatation in rat aorta rings. The response is mainly linked to the activation of soluble guanylate cyclase (sGC), since its inhibition by NS2028 almost abolished relaxation. Indeed PM suspensions stimulated cGMP production in purified isolated SGC. Neither the receptor nor their signaling pathways played a significant role in the direct relaxation by PM or metals. Vasodilatation responses were significantly higher in SHR than WKY control rats.

\section{Conclusion}

Our data demonstrate that PM elicits a dose-dependent vasodilatation via activation of SGC in vascular smooth muscles. PM components, including soluble transition metals play a major role in this response. The stronger effect in SHR rats is in accordance with the observation that acute effects of PM are mainly seen in patients with underlying cardiovascular diseases. 
Toxicology in Vitro Volume 20, Issue 1 , February 2006, Pages 52-62

\section{Introduction}

Numerous epidemiological studies have shown a correlation between particulate air pollution and increases in pulmonary and cardiovascular mortality (e.g.

Dockery et al., 1993 and Peters et al., 2000). Among the hypothesis to explain such an acute effect of particle exposure, both direct and indirect mechanisms have been forwarded. Upon inhalation particles, especially the ultrafine fraction $(<100 \mathrm{~nm})$, can be translocated from the lung to the systemic compartment or taken up in the brain through the olfactory epithelium (Oberdorster, 2004). On the other hand lung inflammation induced by PM (Bagate et al., 2004a) may act as an indirect pathway by the release of some vasoactive mediators which can evoked cardiovascular disturbance.

Our previous studies have demonstrated that intratracheal instillation of PM in spontaneous hypertensive rats (SHR) has a transient effect on vasodilatation of the aorta which was maximal at $4 \mathrm{~h}$ post-instillation. The effect of PM coincided with the blood concentration profile of transition metals but also with the early phase of inflammation. The pulmonary inflammation observed was maximal at $24 \mathrm{~h}$ and coincided with impairment of vasodilatation. These data do not allow for discrimination between the potential mechanisms, but suggest that both a direct effect of metals and inflammation play a role (Bagate et al., 2004a).

Therefore, the current study was performed to elucidate the mechanisms of vasodilatation induced by $\mathrm{PM}$. An impairment of micro-vascular relaxation was reported (Nurkiewicz et al., 2004). The vasoconstriction observed in small pulmonary artery (Brook et al., 2002) and in brachial artery (Batalha et al., 2002) is not likely to be due to direct effects of PM or PM-constituents on vessels. The vasoconstriction response was also not linked to the type of vessel since PMinduced relaxation in both conductance vessel such as aorta and resistance vessels such as the small mesenteric resistance artery (Bagate et al., 2004b). The main difference between our study and those reported by Batalha et al. (2002) and Brook et al. (2002) is that our experiments were carried out in vitro or ex vivo in contrast to in vivo studies made by the other investigators. Several other studies have reported that direct effects of PM on vessels leads to vasodilatation. Total particle suspension (TSP) as well as polycyclic aromatic hydrocarbons (PAHs), the main organic fraction of PM, induce a relaxation in rat aorta (Knaapen et al., 2001 and Kang and Cheng, 1997). The role of endothelium in this relaxation effect of PM is still not clear. TSP-induced relaxation persists after removal of endothelium in rat aorta (Knaapen et al., 2001) and motorcycle exhaust particles also relaxed denuded aorta rings (Cheng and Kang, 1999).

Since the description by Furchgott and Zawadzki (1980) of an absolute requirement of endothelium for the acetylcholine-induced vasodilatation in rabbit aorta, endothelial cells were shown to release a variety of mediators which can act to modulate the mechanical and electrical properties of the vascular smooth muscle cells (Furchgott and Vanhoutte, 1989). These factors include prostacyclin, endothelin, histamine, endothelium-derived relaxing factor (EDRF) and endothelium-derived hyperpolarizing factor (EDHF). Although EDRF was rapidly recognized as nitric oxide (NO) or a compound releasing NO (Palmer et al., 1987 and Ignarro et al., 1987), the identity of EDHF still remains controversial (Quilley et al., 1997 and Mombouli and Vanhoutte, 1997). Endothelium-dependent vasodilatation also occurs by the effect of several physiological mediators including bradykinin, actetylcholine, histamine and substance $\mathrm{P}$, mainly by the activation of their respective receptors. The role of receptors in vasodilatation caused by PM has not yet been established. However, PM is known to activate irritant receptors (capsaicin, substance P and C-GRP) in bronchial epithelial cells. 
By the same way, residual oil fly ashes (ROFA) as well as ultrafine particles have been shown to stimulate epithelial cells and macrophages to increase intracellular calcium and release pro-inflammatory cytokines (Veronesi et al., 1999). PM can also cause the release of several pro-inflammatory and vasoactive mediators (Gilmour et al., 2004) from the lung into the blood (Nemmar et al., 2003). Among those, histamine has been shown to mediate diesel particle induced pulmonary inflammation and peripheral thrombosis via its $\mathrm{H}_{1}$ (Nemmar et al., 2003). PAHs can also induces histamine release from human basophilic cells (Kepley et al., 2003). Three major mediators maybe involved in the vasodilatation response, i.e. prostacyclin, NO and EDHF. The role of these pathways in PM-elicited relaxation is not well understood. Some studies also revealed that these pathways do not contribute to the same degree to vascular relaxation. The NO-dependent mechanisms appear to play an important role in conductance vessels where as EDHF is the main pathway in resistance vessels relaxation (Garland et al., 1995).

Subsequent to our previous in vitro studies on the effects of PM, the aim of the present study was to investigate the involvement of the three major mediators (NO, prostaglandin and EDHF) in PM-elicited vasodilatation in rat aorta and to evaluate the respective contribution of each pathway in the response. The spontaneous hypertensive rat was used, as a model for humans with increased cardiovascular risk with the purpose to compare its response to the wild type Wistar Kyoto (WKY). The PM-mediated vasodilatation was analyzed before and after exclusion of each transduction pathways by selective inhibitors. We evaluated the relative contribution of NO-cGMP and prostanoids by using respective inhibitors of guanylate cyclase and COX. The suppression of the response with high extracellular $\mathrm{K}^{+}$support the contribution of a hyperpolarizing factor. We further investigated the effects of cytochrome P450 inhibition because epoxyeicosatrienoic acids (EETs) are possible candidates for EDHF (Mombouli and Vanhoutte, 1997). The requirement of endothelium and the role of receptors mentioned above in PM response has been verified.

\section{Methods and materials}

\subsection{Animals}

Male Wistar Kyoto (WKY) and spontaneous hypertensive rats (SHR) 13-15 weeks old, were obtained from Harlan Charles River (Germany). Immediately after arrival, the animals were weighed and randomly allocated. Animals were housed in macrolon cages type 3, in a room at constant climate with a $12 \mathrm{~h}$ light/dark cycle (light on at 6:00 h a.m.) and allowed free access to an automatic drinking water system and SSP-Tox standard food (Hope Farms, Woerden, The Netherlands). Basic inspection of animals took place everyday. Experiments were performed in accordance with the guidelines of the Dutch Council for Animals Care and National Institutes of Health and approved by the Animal Care committee of the National Institute of Public Health and Environment, Bilthoven (RIVM), The Netherlands.

\subsection{Chemicals and particles}

The following drugs were used: carbamylcholine chloride (Carbachol), phenylephrine hydrochloride, capsazepine, 17-octadecynoic acid (17-ODYA), pyrilamine, diclofenac (all from Sigma-Aldrich Chemie $\mathrm{GmbH}$, Germany); 4H-8bromo-1,2,4-oxadiazolo(3,4- $d$ )benz $(b)(1,4)$ oxazin-1-one (NS2028) (Calbiochem, Germany), cimetidine (ICN biomedical, Germany). Ketamine (Aesculap, Boxtel, The Netherlands); rompun (Bayer AG, Leverkusen); all other chemicals were of 
Toxicology in Vitro Volume 20, Issue 1 , February 2006, Pages 52-62

pro-analysis quality from Merck (Darmstadt, Germany). Compounds were dissolved in distilled water and freshly prepared with saline before each experiment. NS2028, 17-ODYA and capsazepine were dissolved in 5\% DMSO. Urban air particles (EHC-93) were a kind gift of Dr. Renaud Vincent (Health Effects Institute, Ottawa, Canada) and were recovered from bag-house videlon filters, mechanically sieved though $36 \mu \mathrm{m}$-mesh, removing $50 \%$ of the initial mass. The physico-chemical analyses of EHC can be found in Vincent et al., 1997 and Bagate et al., 2004a. EHC-93 filtrates were obtained by suspending EHC-93 in double distilled water at the desired concentration by 5 min of sonication. Subsequently, the solution was filtered with a syringe adapted on a $0.1 \mu \mathrm{m}$ filter (Minisart RC15, Sartorius AG, Göttingen-Germany). This procedure was shown not to affect the concentration of active soluble metals such as zinc, copper, magnesium and vanadium in the filtrates (personal data).

\subsection{Isolated aorta rings and experimental protocol}

Animals were anaesthetized with an i.p. injection of a mixture of ketamine $(100 \mathrm{mg} / \mathrm{ml})$ and rompun $(20 \mathrm{mg} / \mathrm{ml})$ in a ratio of $10: 4$. The thoracic aorta was rapidly removed and placed in cold modified Krebs-Ringer (KR) solution with the following composition (mM): $\mathrm{NaCl} 118 ; \mathrm{KCl} 5.9 ; \mathrm{CaCl}_{2} 2.5 ; \mathrm{MgSO}_{4} 1.2 ; \mathrm{NaH}_{2} \mathrm{PO}_{4}$ 1.2; $\mathrm{NaHCO}_{3} 24.9 ;$ glucose $11.1, \mathrm{pH}$ was adjusted at 7.4. After cleaning the aorta from fat and connective tissue, it was cut into 2-3 $\mathrm{mm}$ length. During the preparation special care was taken to avoid endothelium damage. For experiment in which the endothelium was removed the rings were gently rubbed over paper tissue. Aortic rings were suspended between two stirrups in a $10 \mathrm{ml}$ organ bath filled with pre-warmed $\left(37{ }^{\circ} \mathrm{C}\right)$ and oxygenated $\left(95 \% \mathrm{O}_{2} / 5 \% \mathrm{CO}_{2}\right)$ modified Krebs buffer. The rings were set at an initial resting tension of $1.5 \mathrm{~g}$ and changes in force were recorded with an isometric force transducer (Harvard Apparatus, Inc., Holliston, MA, USA) connected with a computer equipped with a suitable software program. Before the experiments were started, the preparations were equilibrated for about 60 min with four changes of Krebs solution. Subsequently rings were challenged with $\mathrm{KCl}(80 \mathrm{mM})$ for $2 \mathrm{~min}$, followed by three washes respectively separated by 5,10 and 15 min intervals. The resting tension was readjusted after the third washing. The $\mathrm{KCl}$ challenge and washing procedure were repeated and the final adjustment procedure was performed to achieve the optimal length-tension relation.

\subsection{Evaluation of vasodilator responses}

Cumulative dose response curves using EHC-93 suspension, particle-free filtrate $(10-100 \mu \mathrm{g} / \mathrm{ml}), \mathrm{CuSO}_{4}$ or $\mathrm{ZnSO}_{4}(10-100 \mu \mathrm{M})$ were done, following precontraction with phenylephrine $(0.2 \mu \mathrm{M})$. The endothelium-dependent vasodilatation was tested with carbachol $(10 \mu \mathrm{M})$ after dose-response curve of $\mathrm{EHC}$ in order to verify the functionality of the endothelium. All experiments were performed in the presence of diclofenac $(100 \mu \mathrm{M})$ the non-specific cyclooxygenase inhibitor, in order to prevent involvement of prostaglandin in PM response. Involvement of receptors-dependent pathway were tested by using capsazepine $(100 \mu \mathrm{M})$ a non-specific capsaicin receptor antagonist, pyrilamine $(10 \mu \mathrm{M})$ and cimetidine $(10 \mu \mathrm{M})$ the antagonist of histamine $\mathrm{H}_{1}$ and $\mathrm{H}_{2}$ receptors respectively. The role of NO-cGMP was investigated by NS2028 $(10 \mu \mathrm{M})$ a specific inhibitor of soluble guanylate cyclase, whereas the involvement of cytochrome P450 epoxygenase was evaluate with 17-ODYA $(10 \mu \mathrm{M})$, a non-specific suicide inhibitor of the above enzyme. The role of hyperpolarisation factors was tested by using a depolarising solution $\mathrm{KCl}(40 \mu \mathrm{M})$ to induce pre-contraction of aorta rings. Antagonists and inhibitors were added to baths 15 min prior to EHC-93 and soluble metals induced relaxation. 
Toxicology in Vitro Volume 20, Issue 1 , February 2006, Pages 52-62

The vasodilator responses were evaluated at the maximum of each doseresponse. The results are expressed as percentage reversal of the phenylephrine or $\mathrm{KCl}$-induced pre-contraction.

\subsection{Preparation and determination of soluble guanylate cyclase}

Human soluble guanylate cyclase were prepared from platelet-rich plasma has described previously (Kojda and Noack, 1993 and Weber et al., 2001). The specific activity of soluble guanylate cyclase was measured on the basis of the formation of $\left[{ }^{32} \mathrm{P}\right]$ cGMP from [a- $\left.{ }^{32} \mathrm{P}\right] \mathrm{GTP}$ as described previously (Schultz and Böhme, 1984). Briefly, soluble guanylate cyclase of the single diethylaminoethanol fraction (20-40 $\mathrm{\mu g}$ of protein) was incubated in the total

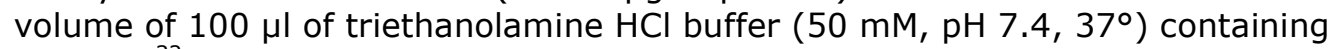
$5 \mathrm{nM}\left[\mathrm{a}^{32} \mathrm{P}\right] \mathrm{GTP}(0.4 \mu \mathrm{Ci}), 100 \mu \mathrm{M}$ GTP, $1 \mathrm{mM}$ cGMP, $1 \mathrm{mM}$ 3-isobutylmethylxanthine, $1 \mathrm{mM} \mathrm{MgCl} 2$ and $1 \mathrm{mM}$ DTT in the presence of $500 \mu \mathrm{M}$ S-nitroso$\mathrm{N}$-acetylpenicillamine (SNAP) or vehicle (0.25\% DMSO). To determine dosedependent effects of SNAP or PM, the assay volume contained concentrations of these drugs or vehicle as indicated by results.

\subsection{Statistical analysis}

Results are expressed as means \pm SEM. Differences were tested for statistical significance by the unpaired Student's $t$-test or one-way variance analysis on repeated measurements when appropriate. Multiple comparisons between groups were performed with Tukey's, Newman Keuls or Dunett post-test. A $p$ value less than 0.05 was considered significant. Non-linear regression analysis were use to determine the $\mathrm{EC}_{50}$. All statistics were run with GraphPad Prism (GraphPad, San Diego, USA).

\section{Results}

\subsection{Characteristics of isolated aorta rings}

The recording of basal vascular tone in the presence of different drugs, did not show any significant modification neither in normal rings nor in endotheliumdenuded rings in both rat strains. A slight increase of basal vascular tone was observed in the presence of NS2028. In contrast capsazepine induced a small decrease in basal vascular tone. No changes was observed in the pre-contraction induced by phenylephrine $(0.2 \mu \mathrm{M})$. Carbachol $(10 \mu \mathrm{M})$ elicited endotheliumdependent relaxation was suppressed in the presence of NS2028 as well as in the presence of its combination with 17-ODYA. This inhibitory effect was observed in both SHR and WKY rats. In endothelium-denuded aorta rings, carbachol induced a vasoconstriction, this response was inhibited by capsazepine. This effect was more obvious in WKY rats than in SHR (Table 1). 
Table 1.

Effect of drugs and inhibitors on the basal vascular tone, contraction and relaxation induced by phenylephrine and carbachol respectively in rat aorta

\begin{tabular}{|c|c|c|c|c|c|c|c|}
\hline \multirow[b]{2}{*}{ Endothelium } & & \multicolumn{2}{|c|}{$\begin{array}{l}\text { Basal vascular tone }{ }^{a} \text { (\% of } \\
\text { contraction) }\end{array}$} & \multicolumn{2}{|c|}{$\begin{array}{l}\text { Phenylephrine }(0.2 \mu \mathrm{M})^{\mathrm{b}}(\Delta \text { increase of vascular } \\
\text { tone, } \mathrm{mg})\end{array}$} & \multicolumn{2}{|c|}{$\begin{array}{l}\text { Carbachol }(10 \mu \mathrm{M})^{\mathrm{c}}(\% \text { of } \\
\text { relaxation })\end{array}$} \\
\hline & & + & - & + & - & + & - \\
\hline Experimental groups & $(n)$ & & & & & & \\
\hline \multicolumn{8}{|l|}{ SHR } \\
\hline Control & $(6)$ & $0.55 \pm 0.01$ & $0.78 \pm 0.23$ & $1.75 \pm 0.18$ & $2.05 \pm 0.16$ & $63.84 \pm 4.94$ & $-0.18 \pm 3.44$ \\
\hline NS2028 & $(4)$ & $6.56 \pm 1.70$ & $5.74 \pm 2.08$ & $2.21 \pm 0.23$ & $2.64 \pm 0.65$ & $11.77 \pm 6.22^{* * *}$ & $-3.67 \pm 1.96$ \\
\hline ODYA & $(5)$ & $1.94 \pm 2.83$ & $-7.52 \pm 4.45$ & $1.88 \pm 0.30$ & $2.09 \pm 0.07$ & $54.87 \pm 9.04$ & $-5.54 \pm 7.1$ \\
\hline NS2028 + ODYA & $(2)$ & $-1.48 \pm 0.15$ & $-2.57 \pm 1.51$ & $2.45 \pm 1.62$ & $2.89 \pm 1.32$ & $4.46 \pm 2.61^{* *}$ & $-2.01 \pm 3.25$ \\
\hline Capsazepine & $(5)$ & $-3.2 \pm 0.81$ & $-8.14 \pm 1.03$ & $1.39 \pm 0.33$ & $1.62 \pm 0.91$ & $60.61 \pm 8.14$ & $5.25 \pm 2.32$ \\
\hline Pyrilamine & $(2)$ & $1.68 \pm 1.33$ & $4.87 \pm 1.89$ & $1.23 \pm 0.57$ & $1.35 \pm 0.60$ & $65.41 \pm 3.59$ & $-3.55 \pm 5.15$ \\
\hline Pyrilamine + cimetidine & $(3)$ & $3.67 \pm 2.63$ & $7.96 \pm 8.69$ & $2.14 \pm 0.23$ & $2.10 \pm 0.10$ & $50.06 \pm 1.75$ & $-4.25 \pm 4.5$ \\
\hline \multicolumn{8}{|l|}{$W K Y$} \\
\hline Control & $(6)$ & $0.42 \pm 0.12$ & $0.68 \pm 0.35$ & $2.32 \pm 0.19$ & $2.71 \pm 0.56$ & $52.71 \pm 5.67$ & $-0.55 \pm 2.09$ \\
\hline NS2028 & $(5)$ & $2.65 \pm 0.86$ & $2.33 \pm 1.97$ & $2.68 \pm 0.16$ & $2.70 \pm 0.07$ & $3.88 \pm 1.29^{* * *}$ & $-2.72 \pm 2.72$ \\
\hline ODYA & $(4)$ & $0.51 \pm 1.47$ & $-0.45 \pm 0.39$ & $2.38 \pm 0.36$ & $3.27 \pm 0.58$ & $48.90 \pm 9.63$ & $2.90 \pm 1.59$ \\
\hline NS2028 + ODYA & $(2)$ & $-0.75 \pm 0.78$ & $-1.26 \pm 0.10$ & $2.42 \pm 0.37$ & $4.43 \pm 0.12$ & $4.55 \pm 0.75^{* *}$ & $-1.49 \pm 0.12$ \\
\hline Capsazepine & $(5)$ & $-2.9 \pm 1.23$ & $0.64 \pm 4.34$ & $2.07 \pm 0.21$ & $2.24 \pm 0.21$ & $49.05 \pm 7.81$ & $11.80 \pm 3.15^{*}$ \\
\hline Pyrilamine & $(2)$ & $-1.43 \pm 0.2$ & $0.01 \pm 0.12$ & $2.79 \pm 0.35$ & $3.21 \pm 0.31$ & $42.01 \pm 0.25$ & $-4.9 \pm 0.23$ \\
\hline Pyrilamine + cimetidine & $(2)$ & $0.94 \pm 1.32$ & $1.42 \pm 0.05$ & $2.60 \pm 0.19$ & $4.97 \pm 0.01$ & $62.10 \pm 1.82$ & $-2.13 \pm 1.92$ \\
\hline
\end{tabular}

${ }^{*} p<0.05,{ }^{* *} p<0.01,{ }^{* * *} p<0.001$ vs control.

a Basal vascular tone of aorta after drugs challenge, expressed in percentage of contraction (negative values mean appearance of relaxation).

${ }^{b}$ Increase of vascular tone elicited by phenylephrine $(0.2 \mu \mathrm{M})$.

${ }^{c}$ Endothelium-dependent relaxation by carbachol $(10 \mu \mathrm{M})$, expressed in percentage of relaxation (negative values mean appearance of contraction). Statistic analysis was evaluated using one-way ANOVA with Dunett post-test comparing all groups to respective controls. 


\subsection{PM and PM filtrate induced vasodilatation in SHR and WKY aorta}

The cumulative concentrations $(10-100 \mu \mathrm{g} / \mathrm{ml})$ of PM suspension and its water soluble components (PM filtrate) elicited a dose-dependent vasodilatation in precontracted rat aorta (Fig. 1a and b). This response started at a low concentration $(10 \mu \mathrm{g} / \mathrm{ml})$ and did not reach the maximum effect at the highest concentration used $(100 \mu \mathrm{g} / \mathrm{ml})$. The relaxation induced by the particle suspension was consistently higher than that induced by the particle filtrate especially in SHR aorta ring. The difference became statistically significant already at $60 \mu \mathrm{g} / \mathrm{ml}$ for $\operatorname{SHR}\left(E_{\max }=27 \%\right.$ vs $8 \%$ ) (Fig. $\left.1 \mathrm{a}\right)$ but only at $100 \mu \mathrm{g} / \mathrm{ml}$ for WKY $\left(E_{\max }=16 \%\right.$ vs $11 \%$ ) (Fig. 1b; Table 2).

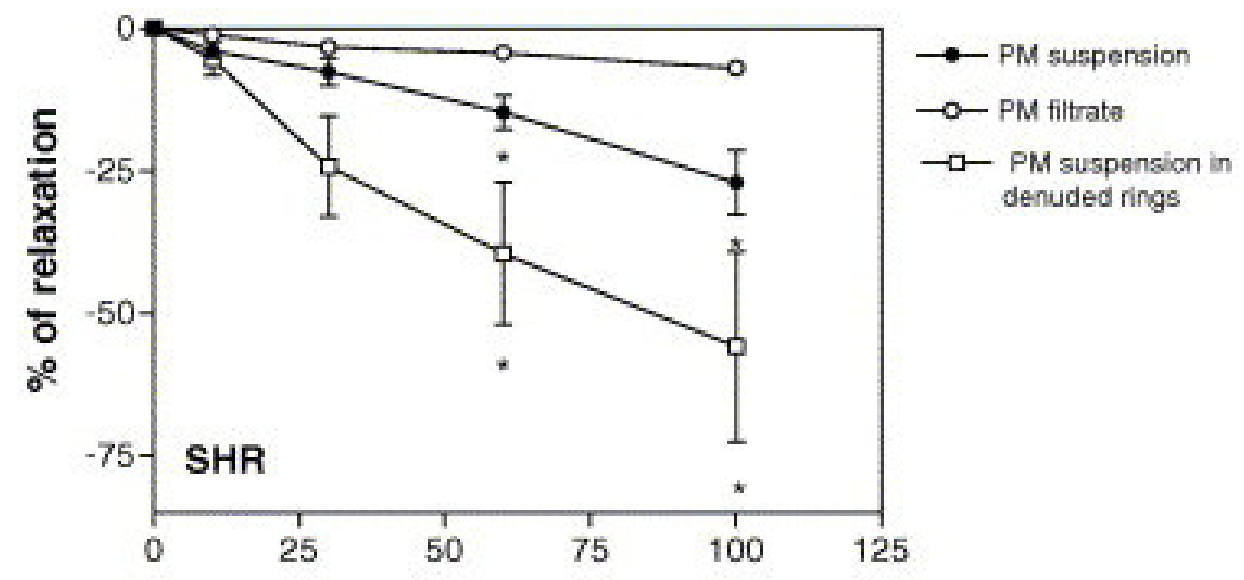

a

Concentrations $(\mu \mathrm{g} / \mathrm{ml})$

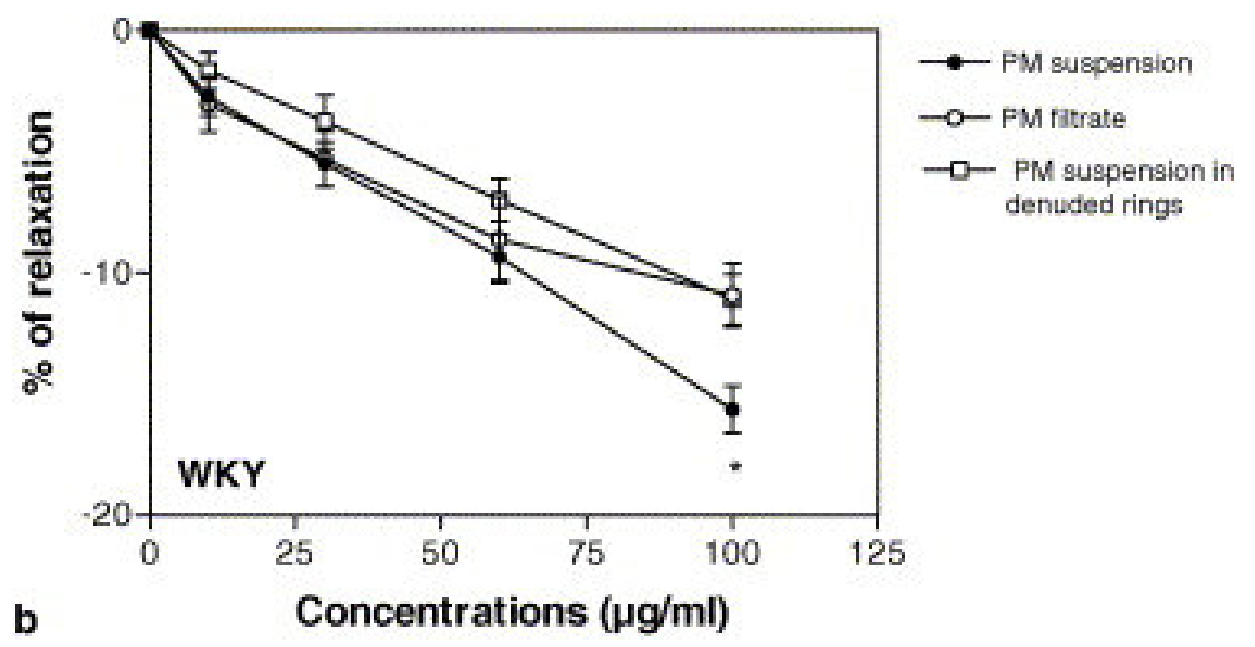

Fig. 1. Concentration-dependent relaxation elicited by particulate matter (PM) and its soluble components in isolated rat aorta of SHR (a) and normal WKY (b) rats. Cumulative concentrations of PM suspension and filtrate $(10-100 \mu \mathrm{g} / \mathrm{ml}, n=4-8)$ were added to aorta rings pre-contracted with phenylephrine $(0.2 \mu \mathrm{M})$. Responses are expressed as percentage of reversal of phenylephrine-induced precontraction. Results are given as means \pm SEM of 4-8 individual experiments for each point. Statistical analysis was done by one-way ANOVA with repeated measures followed by a student Newmann-Keuls test for multiple comparisons. ${ }^{*} p<0.05$ vs PM filtrate. 
Table 2.

Comparison of the relaxation elicited by PM, PM filtrate, copper and zinc on the aorta rings of normal (WKY) and spontaneous hypertensive (SHR)

\begin{tabular}{|c|c|c|c|c|c|c|}
\hline \multirow[b]{2}{*}{ Endothelium } & & \multicolumn{2}{|c|}{$\begin{array}{l}\text { PM suspension }(100 \mu \mathrm{g})(\% \\
\text { of relaxation) }\end{array}$} & \multirow{2}{*}{$\begin{array}{l}\text { PM filtrate } \\
(100 \mu \mathrm{\mu g}) \\
\text { (\% of } \\
\text { relaxation) } \\
+\end{array}$} & \multirow{2}{*}{$\begin{array}{l}\mathrm{CuSO}_{4} \\
(100 \mu \mathrm{M})(\% \text { of } \\
\text { relaxation) }\end{array}$} & \multirow{2}{*}{$\begin{array}{l}\mathrm{ZnSO}_{4} \\
(100 \mu \mathrm{M})(\% \\
\text { of relaxation) } \\
+ \\
\end{array}$} \\
\hline & & + & - & & & \\
\hline SHR & $(7-5-3)$ & $27.06 \pm 5.69^{*}$ & $55.84 \pm 16.70^{8}$ & $7.96 \pm 1.20$ & $56.76 \pm 50.7^{\S \S \S, \$ \$ \$}$ & $24.54 \pm 2.09^{\S \S \S}$ \\
\hline WKY & $(8-6-4)$ & $15.63 \pm 0.98^{*}, \#$ & $11.08 \pm 1.04^{\# \#}$ & $10.91 \pm 1.32$ & $19.47 \pm 3.79^{\$}$ & $14.56 \pm 0.93$ \\
\hline
\end{tabular}

One-way ANOVA with Newmann-Keuls post-test comparing all groups. ${ }^{*} p<0.05$ vs PM filtrate of respective rat type, ${ }^{2} p<0.05$ vs presence of endothelium in $\mathrm{SHR}^{*}{ }^{\#} p<0.05,{ }^{\# \#} p<0.01$ vs SHR. ${ }^{\$} p<0.05,{ }^{\$ \$ \$} p<0.001 \mathrm{CuSO}_{4}$ vs $\mathrm{ZnSO}_{4}$; $\S \S \S$ VS WKY.

In endothelium-denuded aorta rings, a similar vasodilatation was observed with PM suspension. However, the response in these rings was higher than the response in normal rings in SHR $\left(E_{\max }=56 \%\right.$ vs $\left.27 \% p<0.05\right)$ but not in WKY (Fig. $1 \mathrm{a}$ and $\mathrm{b}$; Table 2).

PM-induced vasodilatation was significantly higher in SHR than in WKY $\left(E_{\max }=27 \%\right.$ vs $16 \% p<0.02$ normal rings) and ( $E_{\max }=56 \%$ vs $11 \% p<0.01$ denuded rings) (Table 2 ). These data suggested that SHR are more sensitive to $\mathrm{PM}$-induced relaxation than the wild type WKY.

\subsection{Role of guanylate cyclase and cyclooxygenase in PM suspension induced vasodilatation in SHR and WKY aorta}

The above experiments with PM were repeated in the presence of diclofenac $(100 \mu \mathrm{M})$, a non-specific cyclooxygenase inhibitor in order to access the role of prostacyclin in vasodilatation response of PM suspension. However, no effect of diclofenac was observed in PM induce relaxation (data not shown).

Inhibition of soluble guanylate cyclase by NS2028 $(10 \mu \mathrm{M})$ almost abolished PM $(100 \mu \mathrm{g} / \mathrm{ml})$ induced vasodilatation in both SHR and WKY aorta rings ( $27 \%$ vs $4.9 \% p<0.01, \mathrm{SHR})$ and ( $16 \%$ vs $2 \% p<0.001$, WKY) (Fig. $2 \mathrm{a}$ and b). The same inhibitory effect was observed in the absence of endothelium in both animal vessels $(56 \%$ vs $5 \% p<0.001$, SHR) and $(12 \%$ vs $2 \% p<0.001$, WKY) (Fig. $3 a$ and $b)$. 

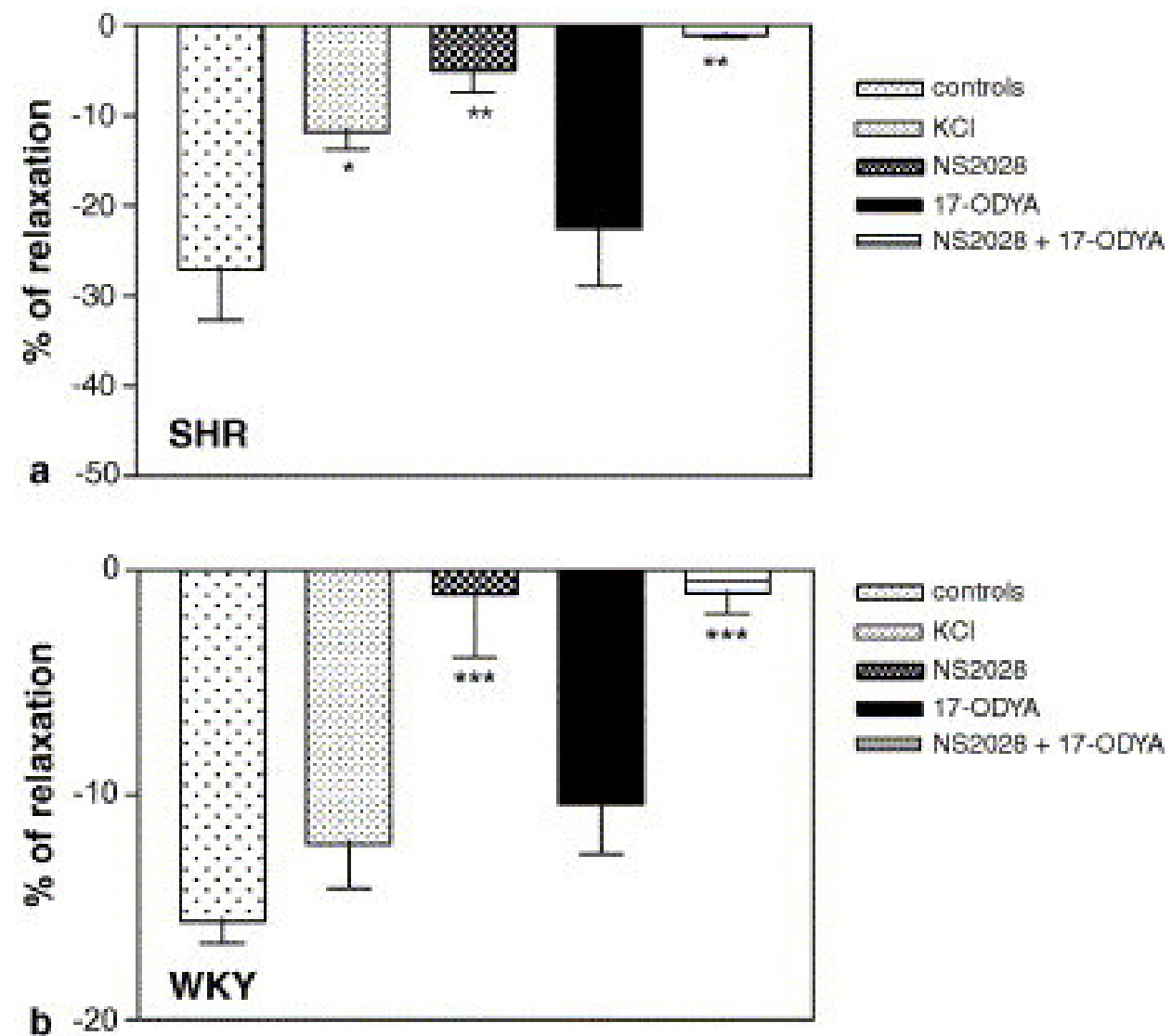

controls

$=0 \mathrm{KCl}$

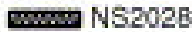

17-ODYA

W NS2O2B + 17-OOYA

Fig. 2. Inhibitory effect of NS2028 (10 $\mu \mathrm{M}), 17-O D Y A(10 \mu \mathrm{M}), \mathrm{KCl}(40 \mathrm{mM})$ on PM-evoked relaxation in isolated rat aorta of SHR (a) and normal WKY (b) rats. Cumulative concentrations of PM suspension and filtrate $(10-100 \mu \mathrm{g} / \mathrm{ml}, n=3-8)$ were added to aorta rings pre-contracted with phenylephrine $(0.2 \mu \mathrm{M})$, in the presence of various inhibitors separately or in combination. Responses are expressed as percentage of reversal of phenylephrine-induced pre-contraction. Results are given as means \pm SEM of 3-8 individual experiments for each point. Statistical analysis was done by one-way ANOVA with repeated measures followed by a student Newmann-Keuls test for multiple comparisons. ${ }^{*} p<0.05,{ }^{* *}$ $p<0.01$ vs control; ${ }^{* * *} p<0.001$ vs control. 


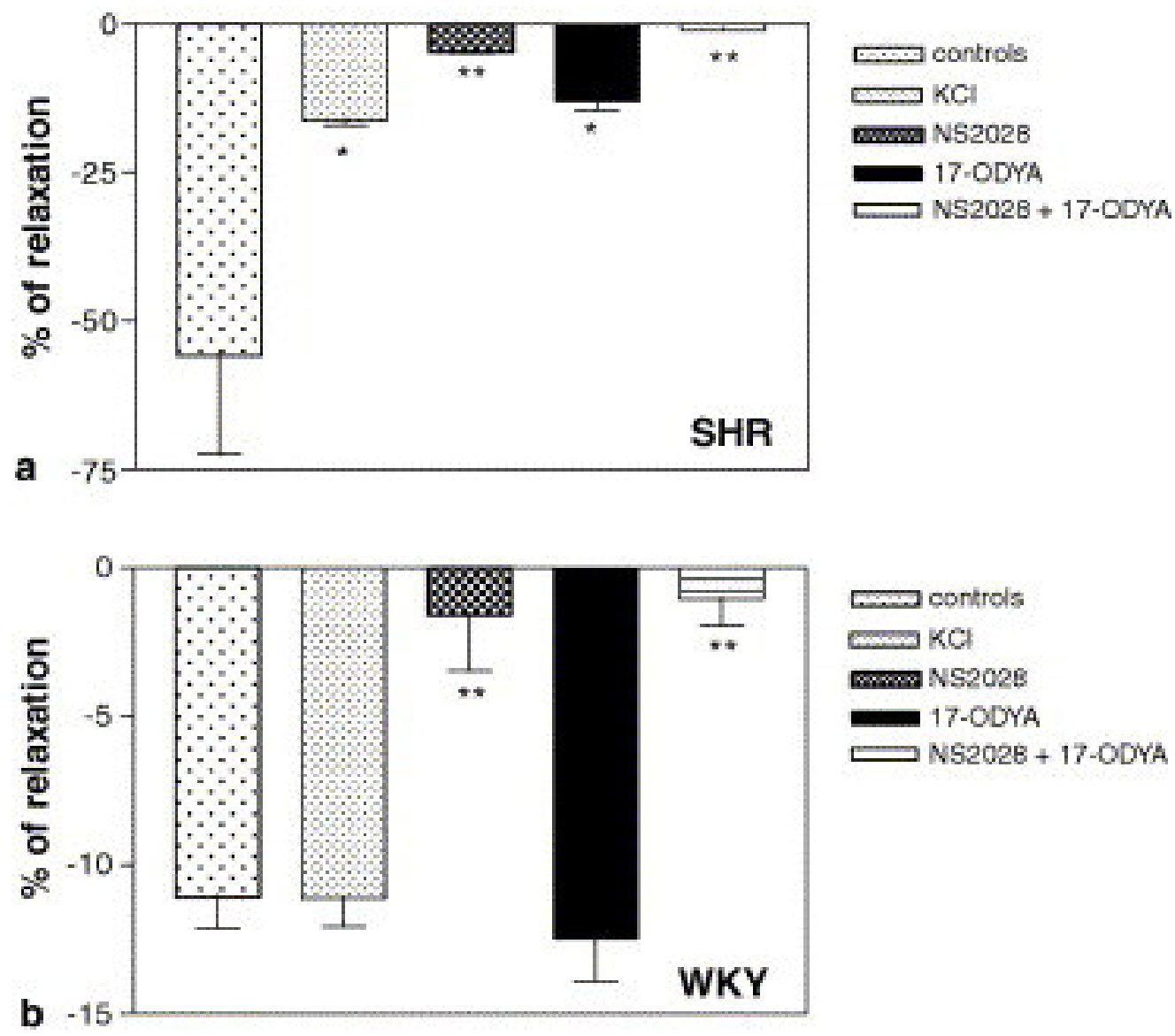

Fig. 3. Inhibitory effect of NS2028 $(10 \mu \mathrm{M}), 17-$ ODYA $(10 \mu \mathrm{M}), \mathrm{KCl}(40 \mathrm{mM})$ on PM-evoked relaxation in denuded rat aorta of SHR (a) and normal WKY (b) rats. Cumulative concentrations of PM suspension and filtrate $(10-100 \mu \mathrm{g} / \mathrm{ml}, n=3-8)$ were added to aorta rings precontracted with phenylephrine $(0.2 \mu \mathrm{M})$, in the presence of various inhibitors separately or in combination. Responses are expressed as percentage of reversal of phenylephrine-induced precontraction. Results are given as means \pm SEM of 3-8 individual experiments for each point. Statistical analysis was done by one-way ANOVA with repeated measures followed by a student Newmann-Keuls test for multiple comparisons. ${ }^{*} p<0.05,{ }^{* *}$ $p<0.01$ vs control.

The relaxation induced by carbachol $(10 \mu \mathrm{M})$ as a control of endotheliumdependent vasodilatation was also inhibited in normal rings. In denuded rings, carbachol-evoked contraction (Table 1).

\subsection{Activation of human platelet isolated soluble guanylate cyclase by PM}

The basal activity of the enzyme preparation was $9.69 \pm 7.31 \mathrm{cGMP} / \mathrm{mg} / \mathrm{min}$ $(n=3)$. Incubation of PM at increasing concentration with the isolated sGC resulted in enhanced formation of cGMP in concentration dependent manner. At the high concentration of PM $(100 \mu \mathrm{g} / \mathrm{ml})$ elicited a release of $39.95 \pm 3.05 \mathrm{cGMP} / \mathrm{mg} / \mathrm{min}(n=3)(\mathrm{Fig} .4)$. The data show that PM can stimulate $\mathrm{sGC}$ to release cGMP. 


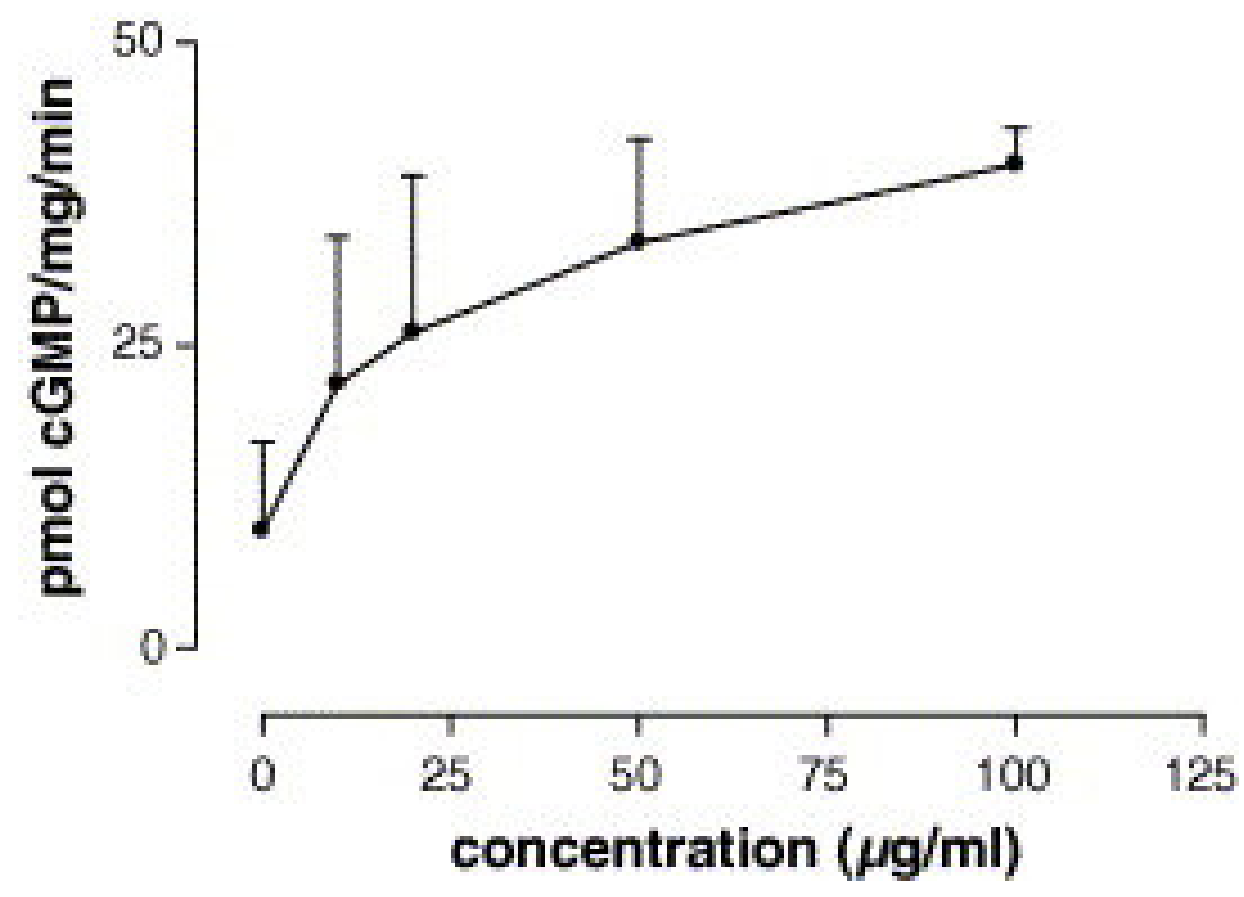

Fig. 4. Release of cGMP by increasing concentrations of PM. Activation of isolated soluble guanylate cyclase after the pre-incubation period with the radio active substrate $\left(a-{ }^{32} \mathrm{P}-\mathrm{GTP}\right)$ and PM suspension $(30-100 \mu \mathrm{g} / \mathrm{ml})$. Results are given as mean \pm SEM of 3 individual experiments for each point.

\subsection{Role of cytochrome $\mathbf{P 4 5 0}$ and high extracellular potassium in PM suspension induced vasodilatation in SHR and WKY aorta}

Inhibition of the release of epoxyeicosatrienoic acid (EET) by cytochrome P450 inhibitor 17-ODYA $(10 \mu \mathrm{M})$ did not modify the vasodilatation induced by PM suspension $(100 \mu \mathrm{g} / \mathrm{ml})$ in aorta rings ( $27 \%$ vs $22 \% \mathrm{~ns}$, SHR) and (15\% vs $12 \% \mathrm{~ns}, \mathrm{WKY}$ ) (Fig. 2a and b). The combination of 17-ODYA (10 $\mu \mathrm{M})$ and NS2028 $(10 \mu \mathrm{M})$ inhibited the relaxation but not more than soluble guanylate cyclase inhibition alone.

The lack of 17-ODYA effect on PM response was also observed in denuded aorta rings of WKY (Fig. 3b). In denuded SHR aorta rings, inhibition of cytochrome P450 elicited a decrease of PM suspension response ( $55 \%$ vs $13 \% p<0.05$, SHR) (Fig. 3a).

PM suspension induced relaxation was reduced in the presence of the high $\mathrm{KCl}$ concentration $(40 \mathrm{mM})$. The reduction of relaxation was statistically significant in SHR aorta but not in WKY ( $27 \%$ vs $12 \% p<0.05$, SHR) and ( $16 \%$ vs $12 \%$ ns, WKY) (Fig. $2 a$ and $b$ ). In denuded rings, the same profile of inhibition was observed ( $56 \%$ vs $7 \% p<0.01, \mathrm{SHR})$ and $(12 \%$ vs $12 \% \mathrm{~ns}, \mathrm{WKY})$ (Fig. 3a and b). Hyperpolarisation occurs in PM-evoked relaxation in SHR aorta but not in WKY. 17-ODYA and $\mathrm{KCl}$ mitigated the relaxation induced by carbachol $(10 \mu \mathrm{M})$ in normal ring. In denuded rings, carbachol elicited contraction (Table 1). 


\subsection{Role of capsaicin and histamine receptors in PM suspension induced vasodilatation in SHR and WKY aorta}

Capsazepine $(100 \mu \mathrm{M})$, a capsaicin receptor antagonist did not inhibit PM-induced vasodilatation. In contrast, a significant increase of relaxation was observed in the presence of capsazepine in aorta rings (27\% vs $45 \% p<0.01, \mathrm{SHR})$ and ( $15 \%$ vs $24 \% p<0.01$, WKY) (Fig. $5 a$ and b).
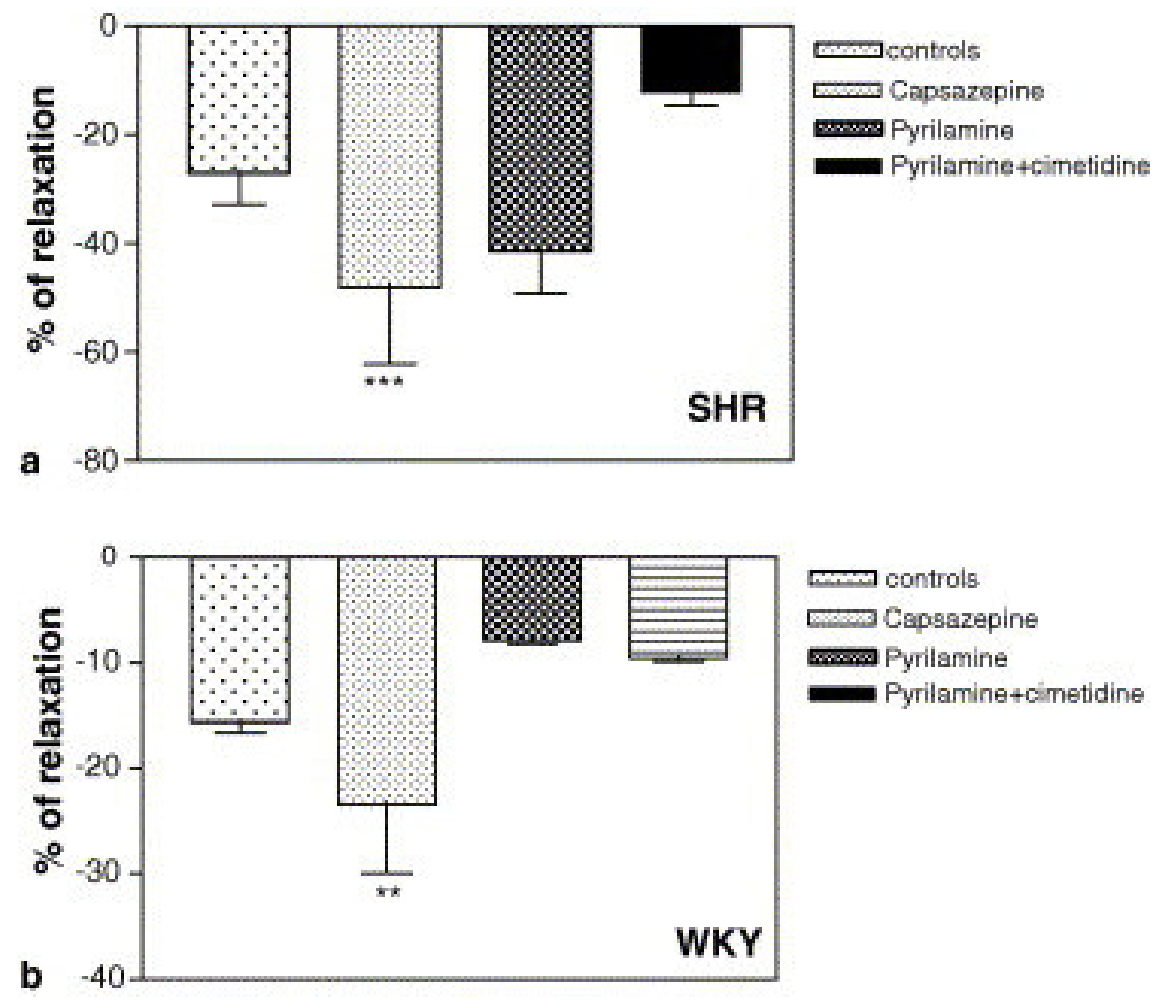

Fig. 5. Effect of capsazepine $(100 \mu \mathrm{M})$, pyrilamine $(10 \mu \mathrm{M})$ and pyrilamine + cimetidine $(10 \mu \mathrm{M})$ on PM-evoked relaxation in rat aorta ring of SHR (a) and normal WKY (b) rats. Cumulative concentrations of PM suspension and filtrate $(10-100 \mu \mathrm{g} / \mathrm{ml}, n=3-8)$ were added to aorta rings pre-contracted with phenylephrine $(0.2 \mu \mathrm{M})$, in the presence of various antagonists separately or in combination. Responses are expressed as percentage of reversal of phenylephrine-induced precontraction. Results are given as means \pm SEM of 3-8 individual experiments for each point. Statistical analysis was done by one-way ANOVA with repeated measures followed by a student Newmann-Keuls test for multiple comparisons. ${ }^{*} p<0.05$ vs control.

Pyrilamine $(10 \mu \mathrm{M})$ a histamine $\mathrm{H}_{1}$ receptor antagonist did not modify the vasodilatation response of PM suspension. The combination of pyrilamine with cimetidine $\mathrm{a}_{2}$ receptor antagonist induced a slight decrease of relaxation elicited by PM. However, this antagonistic effect did not reach statistical significance neither in SHR nor in WKY aorta rings ( $27 \%$ vs $13 \%$, SHR) and (15\% vs $10 \%$, WKY) (Fig. 5a and b).

Although capsazepine did not modify carbachol elicited relaxation it did inhibit its contractile effects in denuded aorta rings in WKY rats (Table 1 ). 


\subsection{Soluble metals also cause vasodilatation in SHR and WKY aorta}

$\mathrm{Zn}^{2+}$ and $\mathrm{Cu}^{2+}$ in the form of their sulfate salts $(10-100 \mu \mathrm{M})$, also induced a dosedependent relaxation of pre-contracted aortic rings (Fig. 6a; Table 2). The vasodilatation elicited by $\mathrm{CuSO}_{4}$ was higher than that induced by $\mathrm{ZnSO}_{4}$ in each animals aorta $\left(E_{\max }=56 \%\right.$ vs $25 \% p<0.001$, SHR) and $\left(E_{\max }=20 \%\right.$ vs $15 \%$ $p<0.05, \mathrm{WKY}$ ) respectively. As with PM suspension, the vasodilatation response induced by metals was also higher in SHR aorta than in WKY vessel $(p<0.001)$. Both metal ions did not affect subsequent relaxation by carbachol (data not shown). The metals induced relaxation was also prevented by inhibition of soluble guanylate cyclase using NS2028 $(10 \mu \mathrm{M})$ in both SHR and WKY aorta rings $(p<0.001)$ (Fig. 6b and c).

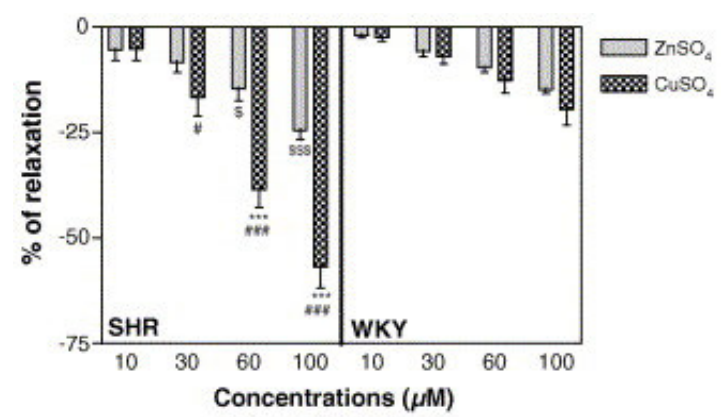

a
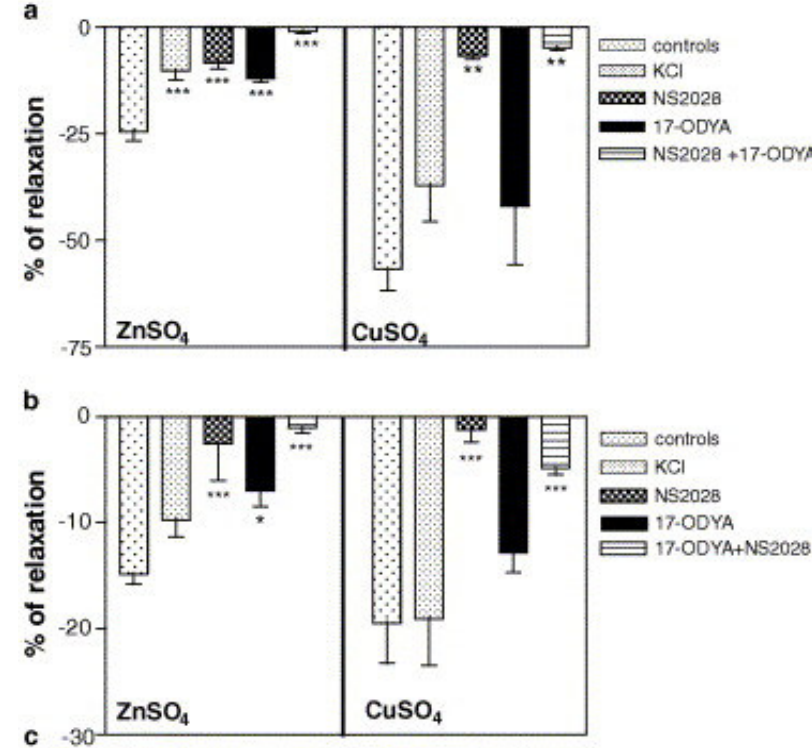

Fig. 6. Concentration-dependent vasodilatation elicited by $\mathrm{CuSO}_{4}$ $(10-100 \mu \mathrm{M})$ and $\mathrm{ZnSO}_{4}(10-$ $100 \mu \mathrm{M})$. Inhibitory effect of NS2028 $(10 \mu \mathrm{M}), 17-$ ODYA $(10 \mu \mathrm{M}), \mathrm{KCl}(40 \mathrm{mM})$.

Cumulative concentrations of soluble metals $(n=3-7)$ were added to aorta rings precontracted with phenylephrine $(0.2 \mu \mathrm{M})$, (a) both rat types, (b) SHR aorta and (c) WKY aorta in the presence of various inhibitors separately or in combination. Responses are expressed as percentage of reversal of phenylephrine-induced precontraction. Results are given as means \pm SEM of 3-7 individual experiments for each point. Statistical analysis was done by one-way ANOVA with repeated measures followed by a student Newmann-Keuls test for multiple comparisons. ${ }^{*} p<0.05$, ${ }^{* *} p<0.01 ;{ }^{* * *} p<0.001$ vs control $(b, c)$ vs $\mathrm{ZnSO}_{4}(\mathrm{a})$ and \# $p<0.05$, \#\# $p<0.01$, \#\#\# $p<0.001 \mathrm{CuSO}_{4}$, SHR vs WKY (a); ${ }^{\$} p<0.05,{ }^{\$ \$ \$} p<0.001$ $\mathrm{ZnSO}_{4}$ SHR vs WKY (a).

\subsection{Role of cytochrome P450 and high extracellular potassium in soluble metals induced vasodilatation in SHR and WKY aorta}

Inhibition of the release of EET acid by 17-ODYA $(10 \mu \mathrm{M})$ did not modify the vasodilatation induced by $\mathrm{CuSO}_{4}(100 \mu \mathrm{M})$ in both animal vessels rings $(56 \%$ vs $42 \% \mathrm{~ns}, \mathrm{SHR})$ and ( $20 \%$ vs $13 \% \mathrm{~ns}, \mathrm{WKY})$ (Fig. $6 \mathrm{~b}$ and c). However EET acid seems to be involved in $\mathrm{ZnSO}_{4}$ elicited relaxation in SHR and in WKY aorta rings. Using the high $\mathrm{KCl}$ concentration $(40 \mathrm{mM})$ as a pre-constrictor, inhibited only $\mathrm{ZnSO}_{4}$ elicited vasodilatation, which is significantly decreased in SHR aorta (25\% vs $11 \% p<0.001$ ) (Fig. 6b). 
Toxicology in Vitro Volume 20, Issue 1 , February 2006, Pages 52-62

\section{Discussion}

The purpose of this study was to elucidate the mechanism of ambient PM-elicited vasodilatation in rat aorta rings. Our present data show that PM and its soluble components elicited an endothelium-independent vasodilatation in rat aortic rings and that this response is due to the activation of soluble guanylate cyclase. No membrane receptors seem to be involved in PM-elicited relaxation.

The first mediator that was investigated is capsaicin. It is the main pungent ingredient in chilli peppers and elicits a sensation of burning by activating sensory neurons via vallinoid receptors (VR). Capsaicin-sensitive sensory nerves are widely distributed in the cardiovascular system and are involved in the regulation of cardiovascular function via endothelium-derived relaxing factors, release of neuropeptide (Vass et al., 1996 and Ralevic et al., 2002) or by opening potassium channels on vascular smooth muscles (Yeon et al., 2001). ROFA has been shown to elicit calcium increase in epithelial cells via activation of VR1 (Veronesi et al., 1999 and Veronesi et al., 2000). In our experiment capsazepine failed to inhibit PM-elicited relaxation, suggesting that VR1 receptors are not involved in PMelicited relaxation in rat aorta.

The second mediator known to be involved in PM effects is histamine. It is a proinflammatory mediator known to play a central role in many pathophysiological processes. It exerts a variety of its effects through the activation of at least three receptors, $\mathrm{H}_{1}, \mathrm{H}_{2}$, and $\mathrm{H}_{3}$ (Barnes, 2001). In the vascular system, histamine effects are mostly mediated via $\mathrm{H}_{1}$ receptors. The activation of this receptor elicited endothelium-dependent vasodilatation (Akerman et al., 2002 and Nakamura et al., 2002). Numerous studies reported that diesel particles or components such as PAHs induce the release of histamine in vitro (Kepley et al., 2003 and Devouassoux et al., 2002) or in vivo (Diaz-Sanchez et al., 2000 and Nemmar et al., 2003). In addition, a histamine $\mathrm{H}_{1}$ receptor antagonist diphenhydramine inhibited diesel elicited inflammation and thrombosis in hamsters (Nemmar et al., 2003). In our study neither pyrilamine alone nor its combination with cimetidine abolished the vasodilatation response of PM. Theses results suggest that PM did not activate histamine receptors but also did not induce histamine release from aorta in our experimental conditions.

Evidence for the third pathway i.e. the NO-cGMP is presented by blocking the PM effect by a specific soluble guanylate cyclase (sGC) inhibitor, and by the release cGMP from purified isolated SGC in the presence of PM. Suggesting that PM could act by direct activation of SGC as an NO donor. The similarity of PM and NO donor was suggested by, first (i), an increase in sensitivity to nitrovasodilators as described in vitro after inhibition of NO synthesis (Moncada et al., 1991 and Busse et al., 1989). Such an increase of PM response has been observed after eNOS inhibition in our previous work (Knaapen et al., 2001). Secondly (ii), in SHR denuded aorta ring, PM response was higher than in intact aorta rings of the same animal. This is also an other characteristic of nitrovasodilators since the release of cGMP by sodium nitroprusside was higher in aorta denuded rings (Moncada et al., 1991 and Shirasaki and Su, 1985). Taken together these findings suggest that PM elicit vasodilatation by activate isolated SGC and evoked a supersensitivity responses in denuded aorta rings. However the remaining question is, how can PM act as an NO donor or interfere with SGC?

$\mathrm{NO}$ is the most important nitrogen-containing species $\left(\mathrm{NO}_{x}\right)$ emitted into the atmosphere from motor traffic, combustion in power stations, home or industrial processes. It is usually present with nitrogen dioxide $\left(\mathrm{NO}_{2}\right)$. $\mathrm{NO}$ and $\mathrm{NO}_{2}$ may inter-convert on a scale-time of seconds in response to sunshine or ozone. They 
also contribute to the atmospheric burden as a result of particle oxidation and condensation to form nitrate aerosol (Holman, 1999). Not surprisingly therefore a release of NO has been reported in several ambient PM samples and four diesel reference materials (Ball et al., 1999). The NO levels ranged from $5 \mathrm{pg}$ of NO per $\mathrm{mg}$ sample at $37^{\circ} \mathrm{C}$ to $1900 \mathrm{ng} / \mathrm{mg}$ at $140{ }^{\circ} \mathrm{C}$. Although we consider this explanation very unlikely and have no data to refer to, such a facilitated NO could explain (i) the direct activation sGC, and (ii) the fact that suspensions have a higher effect than the filtrates, due to sustained release of NO from particles. The carbon monoxide (CO) is a gas emitted from the incomplete combustion of carbon-containing fuels and can be absorbed by PM (Harrison, 1999). Both NO and $\mathrm{CO}$ contained in PM are known to produce relaxation in several tissues by activation of sGC (Kwon et al., 2001 and Lucas et al., 2000). Nitrogen species of $\mathrm{PM}$ can induce production of $\mathrm{NO}$ in airways leading to modulation of bronchial diameter, airway resistance and lower cardiac out put during exercise. It is tempting to speculate that inhaled $\mathrm{NO}_{x}$ stimulate the production of $\mathrm{NO}$ either directly or through incorporation into the $\mathrm{NO}_{x}$ metabolic cycle (formation of $\mathrm{NO}_{2}$, $\mathrm{NO}_{3}, \mathrm{OONO}$ ) (Hazucha, 1999). Peroxide nitrite which is the final metabolite of $\mathrm{NO}_{x}$ cycle has been reported to elicited relaxation in canine cerebral artery via activation of sGC ( $\mathrm{Li}$ et al., 2004). Recently nitrophenol was reported as a vasodilatation compound in diesel particles (Mori et al., 2003). We suggest therefore that PM-elicited relaxation may partly be due to the presence of NOspecies and $\mathrm{CO}$ in PM composition. This is confirmed by our finding with the isolated soluble guanylate cyclase. Although NO-species maybe released from PM and are involved in vasodilatation, other PM components were shown to play a role in this response.

PM contains various soluble metals such as $\mathrm{Zn}, \mathrm{Cu}, \mathrm{V}$ and $\mathrm{Mg}$ (Vincent et al., 1997) that do become bioavailable after intratracheal instillation of PM (Bagate et al., 2004a). In fact in the previous study (Bagate et al., 2004a) we showed that $\mathrm{Cu}, \mathrm{V}$ and $\mathrm{Zn}$ reached plasma levels of 70,62 and 15,000 g/l within $4 \mathrm{~h}$ after intratracheal injection of a model urban PM (EHC-93). We therefore investigated the in vitro effects of the soluble fraction of PM, containing the metals, on vasodilatation. Indeed the soluble fraction of PM induced a dose-dependent vasodilatation in our experiments. Similar response was induced by $\mathrm{Zn}$ and $\mathrm{Cu}$ in concentrations well slightly above those seen in vivo $(10-100 \mu \mathrm{M})$ when administered in their sulfate form to the rat aorta rings. Previously, these metals have been reported to induce relaxation by inhibiting voltage operated channels in vascular smooth muscle (Ma and Li, 1989 and Yang et al., 2001). Such an inhibitory effect can enhance the relaxation effect of NO-species. Indeed $\mathrm{Cu}^{2+}$ caused a NO-dependent vasodilatation in rat aorta (MacKenzie et al., 1999). The vasodilatation elicited by $\mathrm{Zn}^{2+}$ and $\mathrm{Cu}^{2+}$ was also inhibited by the $\mathrm{sGC}$ inhibitor in our experiments, which suggests that these metals also act by stimulating sGC. The role of two divalent cations in NO-cGMP pathway is not well understood. At the eNOS enzyme level, they seem to play a role by maintaining a structurally functional and enzymatically active shaped eNOS, but they are not necessary for the catalytic activity of the enzyme (Perry and Marletta, 1998, Miller et al., 1999 and Hemmens et al., 2000). At the level of sGC, divalent cations may activate the catalytic activity of the enzyme. An intravenous administration of copper leads to a dramatic fall of blood pressure in rats (Cuzzocrea et al., 2003) and copper elicited a release of NO from human pulmonary endothelial cells (Demura et al., 1998). Copper chelators inhibited sodium nitroprusside-induced relaxation (Plane et al., 1997). Magnesium (Mg) is another metal abundantly present in our PM (Bagate et al., 2004a and Vincent et al., 1997) and known to activate sGC. Mg has been reported to induce endothelium-dependent vasodilatation of blood vessels and blood pressure lowering (Yang et al., 2000). Indeed sGCs require divalent cations as substrate cofactors and allosteric modulators to express maximum catalytic activity (Waldman and Murad, 1987). In the presence of $\mathrm{Mg}$ 
Toxicology in Vitro Volume 20, Issue 1 , February 2006, Pages 52-62

and $\mathrm{Mn}$ as substrate cations, sGC exhibits basal catalytic activity that is fully sensitive to ligands (Lucas et al., 2000). These data could explain how PM and its soluble components induce vasodilatation in rat aorta since it contains both nitrogen species and soluble metals that affect vascular modulation.

The other pathway that could play a small role in PM-evoked vasodilatation of SHR aorta is endothelium-derived hyperpolarisation factors (EDHF). The metabolites of cytochrome P450 are well know to elicit hyperpolarisation, but the suicide inhibitor of cytochrome P450 did not modify PM-elicited relaxation. These observations suggest that the slight relaxation that occurs via hyperpolarisation is not due to the metabolites of cytochrome P450. PM, could also activate potassium channels and evoked hyperpolarisation as NO did in rabbit aorta (Bolotina et al., 1994) and in guinea pig carotid (Corriu et al., 1996). On the other hand cGMP release by PM could induce relaxation via hyperpolarisation. The cGMP-dependent protein kinase can activate potassium channels and elicited potassium efflux (Hampl et al., 1996). A contribution of hyperpolarisation in cGMP elicited relaxation has been reported in rat pulmonary arteries (Hampl et al., 1996).

The removal of a basal mediator in some tissues, especially innervated structures, has been suggested to lead to a specific supersensitivity to exogenous application of that mediator (Cannon and Rosenblueth, 1949 and Thesleff, 1960). Based on this hypothesis, a decrease of basal level of NO production in SHR can lead to supersensitivity to PM-elicited vasodilatation. In these rats, the basal activity and protein expression of endothelium NOS in aorta is very low compared to WKY. Although the phenotype is more pronounced in aged SHR, the genetic modification and phenotype is also present in animals up to 12 weeks age animals. An increase of mean arterial pressure and pulse pressure are already present at 3 weeks old (Safar et al., 2001). Since we have used SHR between 13 and 15 weeks old, the PM effect in these animals are more pronounced. The genetic constitution of SHR make them more sensitive to environmental air pollution, working to NO-mediated pathway. Comparative experiments already showed that SHR are more sensitive to PM effects than their wild type WKY (Kodavanti et al., 2000).

In conclusion, our data demonstrate that PM elicits a dose-dependent vasodilatation via activation of SGC in vascular smooth muscles of both SHR and control WKY rats. PM components, such as soluble transition metals seems to play a major role in this in vitro response, although it should be realized that such in vivo plasma levels are only reached at high dose of PM inhalation. That the effect is stronger in SHR rats is in accordance with the observation that acute effects of PM are mainly seen in patients with underlying cardiovascular diseases.

\section{Acknowledgments}

The authors acknowledge Dr. Wim Vleeming for using his laboratory and equipment to perform the ex vivo studies on rat aorta, which were done at the RIVM in Bilthoven. We thank, Ton van de Kuil, A. John F. Boere, Daan Leseman, Jan Bos and Jan Dormans for their technical assistance in animal studies. We also thank Dr. Kojda George for its assistance in isolated guanylate cyclase experiment. Karim Bagaté is a post-doctoral fellow supported by BWPlus 20018 "Systemic effects of particles". 


\section{References}

Akerman et al., 2002 S. Akerman, D.J. Williamson, H. Kaube and P.J. Goadsby, The role of histamine in dural vessel dilation, Brain Res. 956 (2002), pp. 96-102.

Bagate et al., 2004a K. Bagate, J.J. Meiring, M.E. Gerlofs-Nijland, R. Vincent, F.R. Cassee and P.J.A. Borm, Vascular effect of ambient particulate matter instillation in spontaneous hypertensive rats, Toxicol. Appl. Pharmacol. 197 (2004), pp. 29-39.

Bagate et al., 2004b K. Bagate, J.J. Meiring, F.R. Cassee and P.J.A. Borm, The effect of particulate matter on resistance and conductance vessels in rat, Inhal. Tox. 16 (2004), pp. 431-436.

Ball et al., 1999 J.C. Ball, M.D. Hurley, A.M. Straccia and C.A. Gierczak, Thermal release of nitric oxide from ambient air and diesel particles, Environ. Sci. Technol. 33 (1999), pp. 1175-1178.

Barnes, 2001 P.J. Barnes, Histamine and serotonin, Pulm. Pharmacol. Ther. 14 (2001), pp. 329-339.

Batalha et al., 2002 J.R. Batalha, P.H. Saldiva, R.W. Clarke, B.A. Coull, R.C. Stearns, J. Lawrence, G.G. Murthy, P. Koutrakis and J.J. Godleski, Concentrated ambient air particles induce vasoconstriction of small pulmonary arteries in rats, Environ. Health Perspect. 110 (2002), pp. 11911197.

Bolotina et al., 1994 V.M. Bolotina, S. Najibi, J.J. Palacino, P.J. Pagano and R.A. Cohen, Nitric oxide directly activates calcium-dependent potassium channels in vascular smooth muscle, Nature 368 (1994), pp. 850-853.

Brook et al., 2002 R.D. Brook, J.R. Brook, B. Urch, R. Vincent, S. Rajagopalan and F. Silverman, Inhalation of fine particulate air pollution and ozone causes acute arterial vasoconstriction in healthy adults, Circulation 105 (2002), pp. 1534-1536.

Busse et al., 1989 R. Busse, U. Pohl, A. Mulsch and E. Bassenge, Modulation of the vasodilator action of SIN-1 by the endothelium, J. Cardiovasc. Pharmacol. 14 (1989) (Suppl. 11), pp. S81-S85.

Cannon and Rosenblueth, 1949 W.B. Cannon and A. Rosenblueth, The Supersensitivity of Denervated Structures, Macmillan, New York (1949).

Cheng and Kang, 1999 Y.W. Cheng and J.J. Kang, Inhibition of agonist-induced vasocontraction and impairment of endothelium-dependent vasodilatation by extract of motorcycle exhaust particles in vitro, J. Toxicol. Environ. Health A 57 (1999), pp. 75-87.

Corriu et al., 1996 C. Corriu, M. Feletou, E. Canet and P.M. Vanhoutte, Endothelium-derived factors and hyperpolarization of the carotid artery of the guinea-pig, Br. J. Pharmacol. 119 (1996), pp. 959964.

Cuzzocrea et al., 2003 S. Cuzzocrea, T. Persichini, L. Dugo, M. Colasanti and G. Musci, Copper induces type II nitric oxide synthase in vivo, Free Radical Biol. Med. 34 (2003), pp. 1253-1262.

Demura et al., 1998 Y. Demura, S. Ameshima, T. Ishizaki, S. Okamura, I. Miyamori and S. Matsukawa, The activation of eNOS by copper ion $\left(\mathrm{Cu}^{2+}\right)$ in human pulmonary arterial endothelial cells (HPAEC), Free Radical Biol. Med. 25 (1998), pp. 314-320.

Devouassoux et al., 2002 G. Devouassoux, A. Saxon, D.D. Metcalfe, C. Prussin, M.G. Colomb, C. Brambilla and D. Diaz-Sanchez, Chemical constituents of diesel exhaust particles induce IL-4 production and histamine release by human basophils, J. Allergy Clin. Immunol. 109 (2002), pp. 847853.

Diaz-Sanchez et al., 2000 D. Diaz-Sanchez, M. Penichet-Garcia and A. Saxon, Diesel exhaust particles directly induce activate mast cells to degranulate and increase histamine levels and symptom severity, J. Allergy Clin. Immunol. 106 (2000), pp. 1140-1146.

Dockery et al., 1993 D.W. Dockery, C.A. Pope 3rd., X. Xu, J.D. Spengler, J.H. Ware, M.E. Fay, B.G. Ferris Jr. and F.E. Speizer, An association between air pollution and mortality in six U.S. cities, N. Engl. J. Med. 329 (1993), pp. 1753-1759. 
Furchgott and Vanhoutte, 1989 R.F. Furchgott and P.M. Vanhoutte, Endothelium-derived relaxing and constricting factors, FASEB J. 3 (1989), pp. 2007-2018.

Furchgott and Zawadzki, 1980 R.F. Furchgott and J.V. Zawadzki, The obligatory role of endothelial cells in the relaxation of arterial smooth muscle by acetylcholine, Nature 288 (1980), pp. 373-376.

Garland et al., 1995 C.J. Garland, F. Plane, B.K. Kemp and T.M. Cocks, Endothelium-dependent hyperpolarization: a role in the control of vascular tone, TIPS 16 (1995), pp. 23-30.

Gilmour et al., 2004 P.S. Gilmour, A. Ziesenis, E.R. Morrison, M.A. Vickers, E.M. Drost, I. Ford, E. Karg, C. Mossa, A. Schroeppel, G.A. Ferron, J. Heyder, M. Greaves, W. MacNee and K. Donaldson, Pulmonary and systemic effects of short-term inhalation exposure to ultrafine carbon black particles, Toxicol. Appl. Pharmacol. 195 (2004), pp. 35-44.

Hampl et al., 1996 V. Hampl, T.M. Firouzi, E.K. Weir, J.M.C. Huang and S.L. Archer, Cyclic guanosine monophosphate as a hyperpolarizing factor. In: P.M. Vanhoutte, Editor, Endothelium Derived Hyperpolarisation Factors, Harwood Academic Publisher (1996), pp. 153-160.

Harrison, 1999 R.M. Harrison, Measurement of concentrations of air pollutants. In: S.T. Holgate, Editor, Air Pollution and Health, Academic Press (1999), pp. 64-81.

Hazucha, 1999 M.J. Hazucha, Controlled exposure to ozone, nitrogen oxides and acids. In: S.T. Holgate, Editor, Air Pollution and Health, Academic Press (1999), pp. 511-529.

Hemmens et al., 2000 B. Hemmens, W. Goessler, K. Schmidt and B. Mayer, Role of bound zinc in dimer stabilization but not enzyme activity of neuronal nitric-oxide synthase, J. Biol. Chem. 275 (2000), pp. 35786-35791.

Holman, 1999 C. Holman, Sources of air pollution. In: S.T. Holgate, Editor, Air Pollution and Health, Academic Press (1999), pp. 115-148.

Ignarro et al., 1987 L.J. Ignarro, G.M. Buga, K.S. Wood and R.E. Byrns, Endothelium-derived relaxing factor produced and released from artery and vein is nitric oxide, Proc. Natl. Acad. Sci. USA 84 (1987), pp. 9265-9269.

Kang and Cheng, 1997 J.J. Kang and Y.W. Cheng, Polycyclic aromatic hydrocarbons-induced vasorelaxation through activation of nitric oxide synthase in endothelium of rat aorta, Toxicol. Lett. 93 (1997), pp. 39-45.

Kepley et al., 2003 C.L. Kepley, F.T. Lauer, J.M. Oliver and S.W. Burchiel, Environmental polycyclic aromatic hydrocarbons, benzo(a) pyrene (BaP) and BaP-quinones, enhance IgE-mediated histamine release and IL-4 production in human basophils, Clin. Immunol. 107 (2003), pp. 10-19.

Knaapen et al., 2001 A.M. Knaapen, G.J. den Hartog, A. Bast and P.J. Borm, Ambient particulate matter induces relaxation of rat aortic rings in vitro, Hum. Exp. Toxicol. 20 (2001), pp. 259-265.

Kodavanti et al., 2000 U.P. Kodavanti, M.C. Schladweiler, A.D. Ledbetter, W.P. Watkinson, M.J. Campen, D.W. Winsett, J.R. Richards, K.M. Crissman, G.E. Hatch and D.L. Costa, The spontaneously hypertensive rat as a model of human cardiovascular disease: evidence of exacerbated cardiopulmonary injury and oxidative stress from inhaled emission particulate matter, Toxicol. Appl. Pharmacol. 164 (2000), pp. 250-263.

Kojda and Noack, 1993 G. Kojda and E. Noack, Nitric oxide liberating, soluble guanylate cyclase stimulating and vasorelaxing properties of the new nitrate-compound SPM 3672, J. Cardiovasc. Pharmacol. 22 (1993), pp. 103-111.

Kwon et al., 2001 S. Kwon, S. Chung, D. Ahn, D. Yeon and T. Nam, Mechanism of carbon monoxideinduced relaxation in the guinea pig ileal smooth muscle, J. Vet. Med. Sci. 63 (2001), pp. 389-393.

Li et al., 2004 J. Li, W. Li, B.T. Altura and B.M. Altura, Peroxynitrite-induced relaxation in isolated canine cerebral arteries and mechanisms of action, Toxicol. Appl. Pharmacol. 196 (2004), pp. 176182. 
Lucas et al., 2000 K.A. Lucas, G.M. Pitari, S. Kazerounian, I. Ruiz-Stewart, J. Park, S. Schulz, K.P. Chepenik and S.A. Waldman, Guanylyl cyclases and signaling by cyclic GMP, Pharmacol. Rev. 52 (2000), pp. 375-414.

Ma and Li, 1989 X. Ma and X.G. Li, Effects of zinc sulfate on isolated vascular smooth muscles, Yao Xue Xue Bao 2 (1989), pp. 786-788.

MacKenzie et al., 1999 A. MacKenzie, S. Filippini and W. Martin, Effects of superoxide dismutase mimetics on the activity of nitric oxide in rat aorta, Br. J. Pharmacol. 127 (1999), pp. 1159-1164.

Miller et al., 1999 R.T. Miller, P. Martasek, C.S. Raman and B.S. Masters, Zinc content of Escherichia coli-expressed constitutive isoforms of nitric-oxide synthase. Enzymatic activity and effect of pterin, J. Biol. Chem. 274 (1999), pp. 14537-14540.

Mombouli and Vanhoutte, 1997 J.V. Mombouli and P.M. Vanhoutte, Endothelium-derived hyperpolarizing factor(s): updating the unknown, TIPS 18 (1997), pp. 252-256.

Moncada et al., 1991 S. Moncada, D.D. Rees, R. Schulz and R.M. Palmer, Development and mechanism of a specific supersensitivity to nitrovasodilators after inhibition of vascular nitric oxide synthesis in vivo, Proc. Natl. Acad. Sci. A 88 (1991), pp. 2166-2170.

Mori et al., 2003 Y. Mori, K. Kamata, N. Toda, H. Hayashi, K. Seki, S. Taneda, S. Yoshino, A. Sakushima, M. Sakata and A.K. Suzuki, Isolation of nitrophenols from diesel exhaust particles (DEP) as vasodilatation compounds, Biol. Pharm. Bull. 26 (2003), pp. 394-395

Nakamura et al., 2002 Y. Nakamura, H. Matsumoto and K. Todoki, Endothelium-dependent vasorelaxation induced by black currant concentrate in rat thoracic aorta, Jpn. J. Pharmacol. 89 (2002), pp. 29-35.

Nemmar et al., 2003 A. Nemmar, B. Nemery, P.H. Hoet, J. Vermylen and M.F. Hoylaerts, Pulmonary inflammation and thrombogenicity caused by diesel particles in hamsters: role of histamine, Am. J. Respir. Crit. Care Med. 168 (2003), pp. 1366-1372.

Nurkiewicz et al., 2004 T.R. Nurkiewicz, D.W. Porter, M. Barger, V. Castranova and M.A. Boegehold, Particulate matter exposure impairs systemic microvascular endothelium-dependent dilation, Environ. Health Perspect. 112 (2004), pp. 1299-1306.

Oberdorster, 2004 E. Oberdorster, Manufactured nanomaterials (fullerenes, C60) induce oxidative stress in the brain of juvenile largemouth bass, Environ. Health Perspect. 112 (2004), pp. 1058-1062.

Palmer et al., 1987 R.M. Palmer, A.G. Ferrige and S. Moncada, Nitric oxide release accounts for the biological activity of endothelium-derived relaxing factor, Nature 327 (1987), pp. 524-526.

Perry and Marletta, 1998 J.M. Perry and M.A. Marletta, Effects of transition metals on nitric oxide synthase catalysis, Proc. Natl. Acad. Sci. 95 (1998), pp. 11101-11106.

Peters et al., 2000 A. Peters, E. Liu, R.L. Verrier, J. Schwartz, D.R. Gold, M. Mittleman, J. Baliff, J.A. Oh, G. Allen, K. Monahan and D.W. Dockery, Air pollution and incidence of cardiac arrhythmia, Epidemiology 11 (2000), pp. 11-17.

Plane et al., 1997 F. Plane, S. Wigmore, G.D. Angelini and J.Y. Jeremy, Effect of copper on nitric oxide synthase and guanylyl cyclase activity in the rat isolated aorta, Br. J. Pharmacol. 121 (1997), pp. 345-350.

Quilley et al., 1997 J. Quilley, D. Fulton and J.C. McGiff, Hyperpolarizing factors, Biochem. Pharmacol. 54 (1997), pp. 1059-1070.

Ralevic et al., 2002 V. Ralevic, D.A. Kendall, M.D. Randall and D. Smart, Cannabinoid modulation of sensory neurotransmission via cannabinoid and vanilloid receptors: roles in regulation of cardiovascular function, Life Sci. 71 (2002), pp. 2577-2594.

Safar et al., 2001 M. Safar, P. Chamiot-Clerc, G. Dagher and J.F. Renaud, Pulse pressure, endothelium function, and arterial stiffness in spontaneously hypertensive rats, Hypertension 38 (2001), pp. 14161421. 
Toxicology in Vitro Volume 20, Issue 1 , February 2006, Pages 52-62

Shirasaki and Su, 1985 Y. Shirasaki and C. Su, Endothelium removal augments vasodilation by sodium nitroprusside and sodium nitrite, Eur. J. Pharmacol. 114 (1985), pp. 93-96.

Schultz and Böhme, 1984 G. Schultz and E. Böhme, Guanylate cyclaes. In: H.U. Bermeyer, Editor, Methods of Enzymatic Analysis, Vergles Chemie, Weinheim, Germany (1984), pp. 379-389.

Thesleff, $1960 \mathrm{~S}$. Thesleff, Effects of motor innervation on the chemical sensitivity of skeletal muscle, Physiol. Rev. 40 (1960), pp. 734-752.

Vass et al., 1996 Z. Vass, P.B. Brechtelsbauer, A.L. Nuttall and J.M. Miller, Nitric oxide mediates capsaicin-induced increase in cochlear blood flow, Heart Res. 100 (1996), pp. 114-119.

Veronesi et al., 1999 B. Veronesi, M. Oortgiesen, J.D. Carter and R.B. Devlin, Particulate matter initiates inflammatory cytokine release by activation of capsaicin and acid receptors in a human bronchial epithelial cell line, Toxicol. Appl. Pharmacol. 154 (1999), pp. 106-115.

Veronesi et al., 2000 B. Veronesi, M. Oortgiesen, J. Roy, J.D. Carter, S.A. Simon and S.H. Gavett, Vanilloid (capsaicin) receptors influence inflammatory sensitivity in response to particulate matter, Toxicol. Appl. Pharmacol. 169 (2000), pp. 66-76.

Vincent et al., 1997 R. Vincent, S.G. Bjarnason, I.Y.R. Adamason, C. Hedgecock, P. Kumurathasan, J. Guenette, M. Potvin, P. Goegan and L. Bouthillier, Acute pulmonary toxicity of urban particulate matter and ozone, Am. J. Physiol. 15 (1997), pp. 1564-1570.

Waldman and Murad, 1987 S.A. Waldman and F. Murad, Cyclic GMP synthesis and function, Pharmacol. Rev. 39 (1987), pp. 163-196.

Weber et al., $2001 \mathrm{M}$. Weber, N. Lauer, A. Mulsch and G. Kojda, The effect of peroxynitrite on the catalytic activity of soluble guanylyl cyclase, Free Radical Biol. Med. 31 (2001), pp. 1360-1367.

Yang et al., 2000 Z.W. Yang, A. Gebrewold, M. Nowakowski, B.T. Altura and B.M. Altura, Mg(2+)induced endothelium-dependent relaxation of blood vessels and blood pressure lowering: role of NO, Am. J. Physiol.-Regul. Integr. Comp. Physiol. 278 (2000), pp. R628-R639.

Yang et al., 2001 W.M. Yang, Z.Q. Shen, Z.H. Chen, L. Li, F. Peng and W.P. Liu, Effect of copper aspirinate on contraction of isolated rabbit aorta strips, Acta Pharmacol. 22 (2001), pp. 121-124.

Yeon et al., 2001 D. Yeon, S. Kwon, Y. Lee, J. Leem, T. Nam and D. Ahn, Capsaicin-induced relaxation in rabbit coronary artery, J. Vet. Med. Sci. 63 (2001), pp. 499-503. 